\title{
The increasing burden of depression
}

This article was published in the following Dove Press journal:

Neuropsychiatric Disease and Treatment

3I May 20I I

Number of times this article has been viewed

\section{Jean-Pierre Lépine'}

Mike Briley ${ }^{2}$

'Hôpital Lariboisière Fernand Widal, Assistance Publique Hôpitaux de Paris Unité INSERM 705 CNRS UMR 8206, Université Paris Diderot, Paris, France; ${ }^{2}$ NeuroBiz Consulting and Communication, Castres, France
Correspondence: Jean-Pierre Lépine Hôpital Lariboisière Fernand Widal, Assistance Publique Hôpitaux de Paris, 200, rue du Faubourg Saint-Denis 75010 Paris, France

$\mathrm{Tel}+33$ I 40054869

$\mathrm{Fax}+33$ । 40054933

Email jean-pierre.lepine@lrb.ap-hop-paris.fr
Abstract: Recent epidemiological surveys conducted in general populations have found that the lifetime prevalence of depression is in the range of $10 \%$ to $15 \%$. Mood disorders, as defined by the World Mental Health and the Diagnostic and Statistical Manual of Mental Disorders, 4 th edition, have a 12 -month prevalence which varies from 3\% in Japan to over $9 \%$ in the US. A recent American survey found the prevalence of current depression to be $9 \%$ and the rate of current major depression to be 3.4\%. All studies of depressive disorders have stressed the importance of the mortality and morbidity associated with depression. The mortality risk for suicide in depressed patients is more than 20 -fold greater than in the general population. Recent studies have also shown the importance of depression as a risk factor for cardiovascular death. The risk of cardiac mortality after an initial myocardial infarction is greater in patients with depression and related to the severity of the depressive episode. Greater severity of depressive symptoms has been found to be associated with significantly higher risk of all-cause mortality including cardiovascular death and stroke. In addition to mortality, functional impairment and disability associated with depression have been consistently reported. Depression increases the risk of decreased workplace productivity and absenteeism resulting in lowered income or unemployment. Absenteeism and presenteeism (being physically present at work but functioning suboptimally) have been estimated to result in a loss of $\$ 36.6$ billion per year in the US. Worldwide projections by the World Health Organization for the year 2030 identify unipolar major depression as the leading cause of disease burden. This article is a brief overview of how depression affects the quality of life of the subject and is also a huge burden for both the family of the depressed patient and for society at large.

Keywords: epidemiology, DALY, mortality risk, economic burden, family burden, depression

\section{Introduction}

Depression is a common disorder, affecting over 120 million people worldwide. Recent epidemiological surveys conducted in general populations have found that the lifetime prevalence of depression is in the range of $10 \%$ to $15 \%$. Mood disorders as defined by the World Mental Health (WMH) and the Diagnostic and Statistical Manual of Mental Disorders, 4th edition (DSM-IV) have a 12-month prevalence which varies from 3\% in Japan to over 9\% in the US. ${ }^{1}$ Although disorder severity correlates with the probability of treatment in almost all countries, $35.5 \%$ to $50.3 \%$ of serious cases in developed countries and $76.3 \%$ to $85.4 \%$ in less-developed countries received no treatment in the 12 months preceding the interview.

The US Centers for Disease Control (CDC) 2006 and 2008 surveys of 235,067 adults from 45 states plus the District of Columbia, Puerto Rico, and US Virgin Islands 
found the rate of current depression (using the Patient Health Questionaire-8) to be 9\% and the rate of those with a current diagnosis of major depression (DSM-IV criteria) to be $3.4 \%{ }^{2}$ The high female:male sex ratio in the prevalence of depression, especially during the reproductive years, is one of the most replicated findings in epidemiology. ${ }^{3}$ French data from the European Study of the Epidemiology of Mental disorders (ESEMeD) supported this finding - that globally, approximately twice as many women suffered from depression as men. This distribution was true across all age groups with the single exception of the 18 to 24 years age group where there was approximate parity between the sexes (Lépine unpublished data).

A reduction of the classical female:male odds ratio for major depressive disorder was also found in the younger age group (18-34) compared with other age groups in a recent analysis of worldwide surveys. ${ }^{4}$ These authors suggest that the relative decrease in the prevalence of depression in women may be the result of the increase in female opportunities in education, employment, birth control, and other factors increasing gender equality. It will be interesting to see if the more equilibrated female:male sex ratio will persist as this younger cohort ages.

\section{Burden of depression}

Even when successfully treated and remission is achieved, depressive disorders still impose a considerable burden on the patient. Remission is rarely accompanied by a total disappearance of all symptoms. Residual symptoms, especially cognitive impairment or social dysfunction, can continue to reduce performance and cause considerable distress. The ever-present risk of relapse and recurrence also weighs heavily generally reducing the quality of life.

A recent review ${ }^{5}$ reported that the rate of recurrence of major depressive disorder treated in specialized mental health settings was very high (60\% after 5 years, $67 \%$ after 10 years, and $85 \%$ after 15 years) but was significantly lower in the primary care population (35\% after 15 years). As found in other studies ${ }^{6}$ the number of previous episodes and subclinical residual symptoms were the most important predictors of relapse.

\section{Increased mortality risk}

The burden of depressive disorder extends far beyond the disorder itself (Table 1) influencing the mortality risk of the patient. The standardized mortality ratio (SMR) for suicide in patients with unipolar depression is 20.9 in men and 27.0 in women. ${ }^{7}$ In other terms, depressed men and women are
Table I Burden of depression

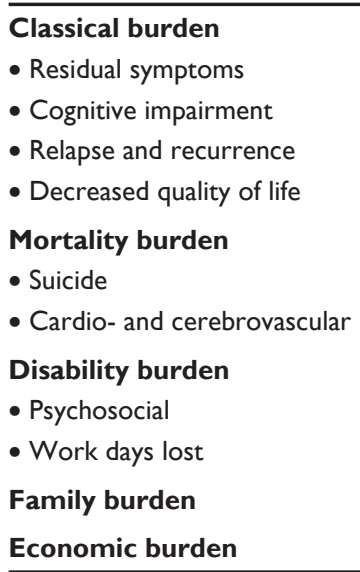

Economic burden

20.9 and 27 times, respectively, more likely to commit suicide than the general population. A 2000 meta-analysis of deaths by suicide concluded that there was a hierarchy in the lifetime prevalence of suicide among patients with affective disorders (Table 2), with patients hospitalized for attempted suicide having an almost 20-fold greater prevalence than subjects who had never had any affective illness. ${ }^{8}$

The risk of cardiac mortality after an initial myocardial infarction is greater in patients with depression and this risk is related to the severity of the depressive episode. A study of 896 patients hospitalized for myocardial infarction found a direct relationship between the severity of the depressive symptoms as measured by the Beck Depression Inventory Score at hospitalization and the risk of cardiac death over the following 5 years. ${ }^{9}$

Similarly, a meta-analysis of 20 studies ${ }^{10}$ has shown that clinical depression is a significant risk factor for mortality in patients with coronary heart disease both short-term (3-6 months; adjusted odds ratio 2.07) and long-term (6-24 months; adjusted odds ratio 2.61).

Another study evaluated long-term mortality risks measured at middle age among 12,866 men with a high risk for coronary heart disease. Greater depressive symptoms were found to be associated with significantly higher risk of allcause mortality and a higher risk of cardiovascular death and, more specifically, stroke mortality. ${ }^{11}$

Table 2 Affective disorders and suicide risk

\begin{tabular}{ll}
\hline Lifetime prevalence of suicide in patients & \\
- Hospitalized at some time in their life for suicidality & $8.6 \%$ \\
- Affective disorders inpatients & $4.0 \%$ \\
- Affective disorders outpatients & $2.2 \%$ \\
- No affective illness & $<0.5 \%$ \\
\hline Compiled from data in reference 8. &
\end{tabular}


Even the risk of death by all causes is increased in depressed patients who are twice as likely to die prematurely compared with the general population (SMR 1.9 men; 2.1 women). ${ }^{?}$

A study of a cohort of 5276 community-dwelling elderly men (aged 68-88 years) in Perth, Australia investigated the 883 deaths (from all causes) occurring during the 6-year follow-up period. ${ }^{12}$ The adjusted mortality hazard (MH) of men with clinical depression was nearly twice $(\mathrm{MH}=1.98)$ that of the total cohort. Furthermore MH increased with the severity of depression from 1.39 for borderline depression to 3.32 for severe depression. The use of antidepressants did not reduce the mortality risk.

Further evidence of increased all cause mortality risk in psychiatric patients has come from study of the GAZEL cohort. ${ }^{13}$ The French GAZEL cohort $(n=19,962$ aged 35-50) used data from the medical department of the French utility company Electricité de France-Gaz de France. Physiciancertified sickness absence records ( $>7$ days) were extracted from administrative files (1990-1992) and were linked to mortality data from France's national registry of mortality (1993-2008, mean follow-up: 15.5 years). Compared with workers with no sickness absence, those absent due to psychiatric disorders had an increased risk of death from suicide, from cardiovascular disease, and from smokingrelated cancer (Table 3).

\section{Functional burden}

An analysis of data from the National Comorbidity Survey Replication, a US nationally representative household survey, ${ }^{14}$ found that overall impairment was significantly higher for mental disorders than for chronic medical disorders. Severe functional impairment was reported by $42 \%$ persons with mental disorders and $24 \%$ with chronic medical disorders. Treatment, however, was provided for a significantly lower proportion of mental (21.4\%) than chronic medical (58.2\%) disorders. Whereas chronic medical disorders are most likely to be associated with impairment in domains of work and home functioning, mental disorders are most commonly associated with problems of social interaction and close relationships.

Psychosocial disability is related to depressive symptom severity during the long-term course of unipolar major depression (MD). ${ }^{15}$ In a study of 371 patients with unipolar MD in the National Institute of Mental Health Collaborative Depression Study, monthly ratings of impairment in life functions and social relationships over an average of 10 years' follow-up were found to be associated with a degree of depressive symptom severity. Significant increases in disability occurred with each stepwise increment in depressive symptom severity (asymptomatic $>$ subthreshold depressive symptoms > symptoms at the minor depression/ dysthymia level $>$ symptoms at the MD level).

Depression is also associated with decreased productivity in the workplace and an increased risk of absenteeism from work. ${ }^{16}$ One study followed 2334 participants, who were employed full or part time and who reported an annual family income of at least US $\$ 25,000$, over a 5 years. The presence of clinical depression, defined as a score $\geq 16$ on the CES depression scale, was related to increased unemployment and decreased annual salary. ${ }^{17}$ Over the 5-year follow-up period $33 \%$ of depressed participants reported new unemployment compared with $21 \%$ of nondepressed participants. After correction for confounding factors the association remained highly significant (odds ratio, $1.6 P=0.001$ ); $17 \%$ of participants with depressive symptoms and $7 \%$ of participants without substantial depressive symptoms at baseline reported that their family income had decreased below US\$25,000 5 years later. This association remained significant after adjusting for potential confounding variables (odds ratio, $1.9 P<0.001$ ).

The National Comorbidity Survey Replication ${ }^{18}$ found that taking into account both absenteeism and presenteeism (being physically present at work but functioning suboptimally) an average of over 27 workdays per year were lost per depressed employee representing an annual individual loss of US $\$ 4400$. At a national level, this translates into a loss of US $\$ 36.6$ billion per year in the US.

\section{Family burden}

Problems of social dysfunction, ${ }^{19}$ decreased income resulting from workplace absenteeism, underperformance or unemployment (see above) are a burden for the patient and the patient's partner and family. At a time when the depressed patient is at greatest need of social support, depression tends to disrupt family stability frequently leading to separation or divorce. The link between depression and divorce can be bi-directional. A study using the longitudinal component of the Canadian

Table 3 Sickness absence due to psychiatric disorder and mortality

\begin{tabular}{lll}
\hline & HR & Adjusted HR \\
\hline Suicide & 6.01 & 5.13 \\
Cardiovascular disease & 1.84 & 1.59 \\
Smoking-related cancer & 1.65 & 1.31 \\
\hline
\end{tabular}

Notes: $\mathrm{HR}=$ hazard ratio over a mean of 15.5 years in workers with absence ( $>7$ days) due to a psychiatric disorder compared with workers with no sickness absence. Adjusted HR, adjusted for marital status, tobacco smoking, and alcohol use. Based on data from the French GAZEL cohort ( $n=19,962$ aged 35-50 years) and the French national registry of mortality (1993-2008). Compiled from data in reference 13. 
National Population Health Survey (1994/1995 through 2004/2005) examined the relationship between the dissolution of a marital or cohabiting relationship and subsequent depression among Canadians aged 20 to 64 years..$^{20}$ For both sexes, dissolution of a marriage or cohabiting relationship was associated with higher odds of a new episode of depression, compared with those who remained with a spouse or partner over the 2-year period following the depressive episode. Marital dissolution was more strongly associated with depression among men than among women.

Depression in women during pregnancy is common. Prevalence rates have been reported to be $7.4 \%, 12.8 \%$, and $12.0 \%$ for the first, second, and third trimesters, respectively. ${ }^{21,22}$ Other studies have shown that $10 \%$ to $16 \%$ of pregnant women fulfill the diagnostic criteria for $\mathrm{MD}$, and even more women experience subsyndromal depressive symptoms. ${ }^{23}$ Some of the numerous risks of maternal depression for the fetus, the newborn baby, and its subsequent development are summarized in Table 4.

\section{DALY measurements and predictions}

DALY, disability adjusted life-years, is the sum of life-years lost due to premature death and years lived with disability adjusted for severity. ${ }^{23}$ It integrates the notions of individual mortality and disability with global disease prevalence. Using the DALY, unipolar MD was classed in 1990, as the fourth leading burden of disease or injury cause worldwide for both sexes, behind lower respiratory infections, diarrheal diseases, and perinatal disorders. ${ }^{24}$ By 2004 it had moved up to third place and World Health Organization projections ${ }^{25}$ estimate that it will be the leading cause of disease burden worldwide by 2030 .

\section{Conclusion}

Depression has a high prevalence worldwide in both developed and developing countries. In addition to the profound effects on the quality of life of the patient, depression has a major

Table 4 Burden of maternal depression fetal risks

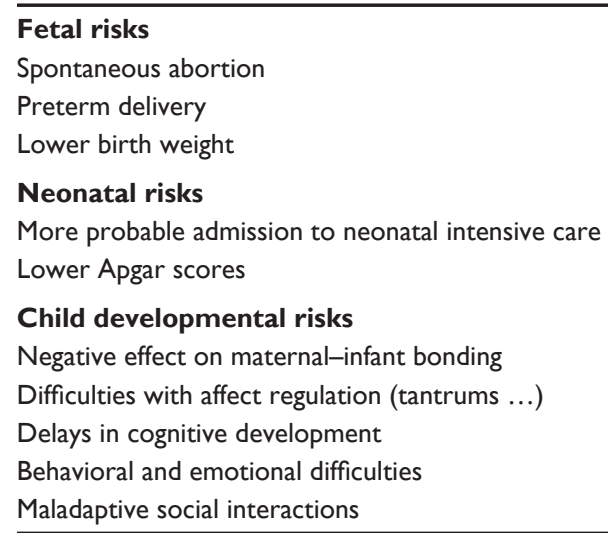

impact on mortality risk by suicide, and on cardiovascular and other diseases as well as death by all causes. Depression impairs cognitive and social functioning leading to decreased performance in the workplace and elsewhere. This dysfunction has considerable economic impact on the individual, his or her family, his or her employer, and on society at large. Depression, especially maternal depression, affects the health and development of the baby with possible long-term consequences for the mental health of future generations.

In view of the profound and widespread burden caused by depression it is hardly surprising that analysis of DALYs puts depression among the leading causes of burden of diseases worldwide. As the infectious diseases, especially in developing countries, are progressively controlled, depression is predicted to become the major health burden worldwide. Thus prevention and treatment of depression must be seen as a priority medical challenge for the 21 st century.

\section{Disclosure}

Professor Lépine has received honoraria from Pfizer-Wyeth, Pierre Fabre Médicament, and Servier. Dr Mike Briley is a consultant for Pierre Fabre Médicament, Asahi Kasei Pharma, Germania Pharmaceutica, Janssen Pharmaceutica, and Cypress BioScience.

\section{References}

1. Demyttenaere K, Bruffaerts R, Posada-Villa J, et al. Prevalence, severity, and unmet need for treatment of mental disorders in the World Health Organization World Mental Health Surveys. JAMA. 2004;291:2581-2590.

2. Centers for Disease Control and Prevention (CDC). Current depression among adults - United States, 2006 and 2008. Morb Mortal Wkly Rep. 2010;59:1229-1235.

3. Grigoriadis S, Robinson GE. Gender issues in depression. Ann Clin Psychiatry. 2007;19:247-255.

4. Seedat S, Scott KM, Angermeyer MC, et al. Cross-national associations between gender and mental disorders in the World Health Organization World Mental Health Surveys. Arch Gen Psychiatry. 2009;66: 785-795.

5. Hardeveld F, Spijker J, De Graaf R, Nolen WA, Beekman AT. Prevalence and predictors of recurrence of major depressive disorder in the adult population. Acta Psychiatr Scand. 2010;122:184-191.

6. Ten Doesschate MC, Bockting CL, Koeter MW, Schene AH; DELTA Study Group. Prediction of recurrence in recurrent depression: a 5.5year prospective study. J Clin Psychiatry. 2010;71:984-991.

7. Osby U, Brandt L, Correia N, Ekbom A, Sparén P. Excess mortality in bipolar and unipolar disorder in Sweden. Arch Gen Psychiatry. 2001;58: 844-850.

8. Bostwick JM, Pankratz VS. Affective disorders and suicide risk: a reexamination. Am J Psychiatry. 2000;157:1925-1932.

9. Lespérance F, Frasure-Smith N, Talajic M, Bourassa MG. Five-year risk of cardiac mortality in relation to initial severity and one-year changes in depression symptoms after myocardial infarction. Circulation. 2002;105:1049-1053.

10. Barth J, Schumacher M, Herrmann-Lingen C. Depression as a risk factor for mortality in patients with coronary heart disease: a meta-analysis. Psychosom Med. 2004;66:802-813. 
11. Gump BB, Matthews KA, Eberly LE, Chang YF; MRFIT Research Group. Depressive symptoms and mortality in men: results from the Multiple Risk Factor Intervention Trial. Stroke. 2005;36: 98-102.

12. Almeida OP, Alfonso H, Hankey GJ, Flicker L. Depression, antidepressant use and mortality in later life: the Health In Men Study. PLoS One. 2010;5:e11266.

13. Melchior M, Ferrie JE, Alexanderson K, et al. Does sickness absence due to psychiatric disorder predict cause-specific mortality? A 16-year follow-up of the GAZEL occupational cohort study. Am J Epidemiol. 2010;172:700-707.

14. Druss BG, Hwang I, Petukhova M, Sampson NA, Wang PS, Kessler RC. Impairment in role functioning in mental and chronic medical disorders in the United States: results from the National Comorbidity Survey Replication. Mol Psychiatry. 2009;14:728-737.

15. Judd LL, Akiskal HS, Zeller PJ, et al. Psychosocial disability during the long-term course of unipolar major depressive disorder. Arch Gen Psychiatry. 2000;57:375-380.

16. Broadhead WE, Blazer DG, George LK, Tse CK. Depression, disability days, and days lost from work in a prospective epidemiologic survey. JAMA. 1990;264:2524-2528.

17. Whooley MA, Kiefe CI, Chesney MA, Markovitz JH, Matthews K, Hulley SB. Depressive symptoms, unemployment, and loss of income: The CARDIA Study. Arch Intern Med. 2002;162:2614-2620.

18. Kessler RC, Akiskal HS, Ames M, et al. Prevalence and effects of mood disorders on work performance in a nationally representative sample of US workers. Am J Psychiatry. 2006;163:1561-1568.
19. Briley M, Moret C. Improvement of social adaptation in depression with serotonin and norepinephrine reuptake inhibitors. Neuropsychiatr Dis Treat. 2010;6:647-655.

20. Rotermann M. Marital breakdown and subsequent depression. Health Rep. 2007;18:33-44.

21. Bennett HA, Einarson A, Taddio A, Koren G, Einarson TR. Depression during pregnancy: overview of clinical factors. Clin Drug Investig. 2004;24:157-179.

22. Bennett HA, Einarson A, Taddio A, Koren G, Einarson TR. Prevalence of depression during pregnancy: systematic review. Obstet Gynecol. 2004;103:698-709.

23. Marcus SM, Heringhausen JE. Depression in childbearing women: when depression complicates pregnancy. Prim Care. 2009;36:151-165.

24. Murray CJ, Lopez AD. Global mortality, disability, and the contribution of risk factors: Global Burden of Disease Study. Lancet. 1997;349. 1436-1442.

25. World Health Organization. The global burden of disease: 2004 update. 2004 http://www.who.int/entity/healthinfo/global_burden_disease/ GBD_report_2004update_full.pdf.

26. Bonari L, Pinto N, Ahn E, Einarson A, Steiner M, Koren G. Perinatal risks of untreated depression during pregnancy. Can J Psychiatry. 2004;49:726-735.

27. Fishell A. Depression and anxiety in pregnancy. J Popul Ther Clin Pharmacol. 2010;17:e363-e369.
Neuropsychiatric Disease and Treatment

\section{Publish your work in this journal}

Neuropsychiatric Disease and Treatment is an international, peerreviewed journal of clinical therapeutics and pharmacology focusing on concise rapid reporting of clinical or pre-clinical studies on a range of neuropsychiatric and neurological disorders. This journal is indexed on PubMed Central, the 'PsycINFO' database and CAS, and is the official journal of The International Neuropsychiatric Association (INA). The manuscript management system is completely online and includes a very quick and fair peer-review system, which is all easy to use. Visit http://www.dovepress.com/testimonials.php to read real quotes from published authors. 